\title{
Reduced Life Expectancy Model Analyses of Exposure Time Effects of Endocrine Disruptors to Teleost Fishes Based on Effect Concentration of Hepatic Biomarkers
}

\author{
Mengtian Sun, Hualong Chen, Ling Zhao* \\ School of Environment, Jinan University, Guangzhou, China \\ Email: *zhaoling@jnu.edu.cn
}

How to cite this paper: Sun, M.T., Chen, H.L. and Zhao, L. (2020) Reduced Life Expectancy Model Analyses of Exposure Time Effects of Endocrine Disruptors to Teleost Fishes Based on Effect Concentration of Hepatic Biomarkers. Journal of Environmental Protection, 11, 540-550.

https://doi.org/10.4236/jep.2020.117032

Received: June 7, 2020

Accepted: July 26, 2020

Published: July 29, 2020

Copyright $\odot 2020$ by author(s) and Scientific Research Publishing Inc. This work is licensed under the Creative Commons Attribution International License (CC BY 4.0).

http://creativecommons.org/licenses/by/4.0/

\begin{abstract}
In this current paper, the exposure time effects on four endocrine disruptors and teleost fishes were evaluated using the reduced life expectancy (RLE) model based on the effect concentration $\left(\mathrm{EC}_{50}\right)$ of available literature published. The result on the regression analysis over different exposure times has demonstrated that the $\mathrm{EC}_{50}$ of hepatic biomarkers falls with increasing exposure times in a predictable manner. The slopes of the regression equations reflect the strength of the toxic effects on the various teleost fish. The $\mathrm{EC}_{50}$ reduction over time can be interpreted based on the bioconcentration process, which can be used to understand transfer routes of the compounds from water to fish body. RLE model also provides useful information in assessing the toxic effects on fish life expectancy as a result of the occurrence of compounds.
\end{abstract}

\section{Keywords}

Reduced Life Expectancy Model, Endocrine Disruptors, Effect Concentration, Hepatic Biomarkers, Teleost Fishes

\section{Introduction}

The endocrine disruptors are chemicals that may interfere with the body's endocrine system and produce genotoxicity, reproductive toxicity, carcinogenic and metabolic disorders in both humans and wildlife [1] [2] [3] [4]. The chemicals that are known endocrine disruptors include $17 \alpha$-ethynylestradiol $\left(\mathrm{EE}_{2}\right)$, bisphenol A (BPA) and nonylphenol (NP). Endocrine disruptors can be interfere or 
block the way natural hormones ( $17 \beta$-estradiol, $\mathrm{E}_{2}$ ) binding to their receptors, or altering metabolism in the liver and $v t g$ mRNA expression [4] [5]. Due to the low water solubilities and high octanol-water partition coefficients, endocrine disruptors are relatively stable in the environment [6] [7]. Therefore, it is important to study the estrogen effects of endocrine disruptors on organisms and to evaluate the potential risks of endocrine disruptors to the environment.

The teleost fishes also has about high genetic homology to humans, which are a popular model organism for studying molecular toxicology in vitro and in vivo of the endocrine disrupters [8] [9]. The vtg genes or VTG protein can be used as hepatic biomarkers to appraise the effect of endocrine disrupters [10] [11]. Many toxicological studies usually focus on concentration-response relationship based on biomarker in risk assessments. Relatively fewer studies exposure time has been studied as a quantifiable variable of toxic effects [12]. Reduced life expectancy (RLE) model which is based on the influence of exposure time has been developed to study time-response relationship [13]. Therefore, it is of significant for assessing the exposure time effect to hepatic biomarkers of teleost fishes due to the endocrine disrupters using the RLE model.

In previous study with zebrafish [5] was evaluated the relationship between exposure time and the $\mathrm{EC}_{50}$ of hepatic biomarkers based on the analogy of RLE model. It was noted that the relationship between natural logarithm of exposure time $\left(\operatorname{lnET}_{50}\right)$ and $\mathrm{EC}_{50}$ for zebrafish was linear. The RLE model allows the normal life expectancy (NLT) to be calculated from the toxicity data [12]. In previous study, the reported NLT and calculated NLT obtained were in general agreement [5]. The published literature has mainly focuses on the application of RLE model for the exposure time effect of a certain fish, but there are few studies on whether the relationship between $\mathrm{EC}_{50}$ and exposure time of different types of fishes can be described using the RLE model.

The objectives of present study were to explore the RLE model for teleost fish based on the toxicological data of endocrine disruptors available in the literature published. The characteristics obtained from analogy of the RLE model would be used to analyze the relationship of exposure time with $\mathrm{EC}_{50}$ of hepatic biomarkers and for estimation of effects and routes of the $\mathrm{EC}_{50}$ reduction on fish life expectancy. The research results are of significance for the risk assessment of different types organisms as a result of endocrine disruptors in the environment.

\section{Methodology}

\subsection{Organisms and Compounds Selected for Evaluations}

Teleost fish were selected as organisms for this study since lots of toxic effects data related to this fish are available. Teleost fish are key components of both marine and freshwater food chains and serve as one of the important source of food for human [14] [15]. Thus teleost fish have a key role to play in the trophic structure of aquatic ecosystems, vital for energy transfer between the trophic levels [16]. It would be significant to evaluate the effects of exposure time on such 
a key component of aquatic systems. Zebrafish, fathead minnow, brown trout, and rainbow trout are the organisms selected for study (Table 1). Toxicants having similar toxic mechanism are selected for this study and they included known endocrine disruptors ( $\mathrm{EE}_{2}, \mathrm{BPA}$ and $\left.\mathrm{NP}\right)$ and natural hormones $\left(\mathrm{E}_{2}\right)$. Among these toxicants enter the environment through human activities [2] [17].

\subsection{Sources and Collection of Data}

Toxic effects data related to teleost fish with these particular endocrine disruptors were obtained from the literature published (Table 1). These data sets include $\mathrm{EC}_{50}$ for hepatic biomarkers ( $\mathrm{tg}$ genes or VTG protein) of teleost fish at different exposure times. The liver is an organ mainly characterized by metabolic function in the teleost fish [18] [19], so it is of significance to select hepatic biomarkers as research targets. The data obtained from the literature are in various units for concentration such as $\mathrm{ng} / \mathrm{L}-\mu \mathrm{g} / \mathrm{L}$. For consistency all units were converted into g/L. Similarly exposure time was also expressed in various units (hours and days) of time and all were converted into days (d). The NLT data of each organism was also obtained from literature published.

\subsection{Reduction Life Expectancy (RLE) Model}

The linear RLE model [20] was developed with the use of the concept of reduction in life expectancy and the model equation is given below:

Table 1. Reported values based on the $\mathrm{EC}_{50}$ values of VTG or vtg gene expressions for endocrine disrupters with different types of teleost fishes.

\begin{tabular}{|c|c|c|c|c|}
\hline Compounds & Fish & Observed $\mathrm{EC}_{50}$ & Exposure time (day) & Reference \\
\hline \multirow{4}{*}{$\mathrm{E}_{2}(\mathrm{ng} / \mathrm{L})$} & zebrafish & 41.2 & 8 & {$[30]$} \\
\hline & & 15.1 & 12 & {$[31]$} \\
\hline & Drown trout & 15 & 14 & {$[32]$} \\
\hline & fathead minnow & 25 & 14 & {$[33]$} \\
\hline \multirow{5}{*}{$\mathrm{EE}_{2}(\mathrm{ng} / \mathrm{L})$} & & 60.7 & 5 & [34] \\
\hline & zebrafish & 30.46 & 5 & {$[35]$} \\
\hline & & 2.51 & 8 & {$[30]$} \\
\hline & brown trout & 5.2 & 12 & {$[31]$} \\
\hline & fathead minnow & 0.9 & 14 & [33] \\
\hline \multirow{5}{*}{ BPA $(\mu \mathrm{g} / \mathrm{L})$} & & 248.11 & 6 & \\
\hline & zebrafish & 193.88 & 9 & {$[5]$} \\
\hline & & 183.26 & 12 & \\
\hline & fathead minnow & 158 & 14 & {$[33]$} \\
\hline & zebrafish & 166.29 & 15 & {$[5]$} \\
\hline \multirow{3}{*}{$\mathrm{NP}(\mu \mathrm{g} / \mathrm{L})$} & rainbow trout & 14.14 & 8 & {$[36]$} \\
\hline & brown trout & 6.9 & 12 & {$[31]$} \\
\hline & fathead minnow & 7.02 & 14 & [33] \\
\hline
\end{tabular}




$$
\mathrm{LC}_{50}=-a \ln \mathrm{LT}_{50}+b
$$

Equation (1) is where $\mathrm{LC}_{50}$ is the lethal concentration, $\mathrm{LT}_{50}$ is the exposure time, $\mathrm{NLT}_{50}$ is the normal life expectancy of the organism, $d$ is a constant, $a$ is $1 / d$ and $b$ is $\operatorname{lnNLT} \mathrm{T}_{50} / d$.

Consistent with previous studies, $\mathrm{LC}_{50}$ and $\mathrm{EC}_{50}$ are frequently used in various tissues as toxicity endpoints, which is related to nominal concentration and $\log$ Kow (octanol partition coefficient) [21]. Consequently, the relationship could be extended from the $\mathrm{LC}_{50}$ to the $\mathrm{EC}_{50}$ in the RLE model. Based on this extension a RLE model [5] for estrogenic effect was proposed and may be described by the equation given below:

$$
\mathrm{EC}_{50}=-a \ln \mathrm{ET}_{50}+b
$$

Equation (2) is where $\mathrm{EC}_{50}$ is the effective concentration, $\mathrm{ET}_{50}$ is the exposure time, $\mathrm{NLT}_{50}$ is the normal life expectancy of the organism, and $a$ and $b$ are constants as prefiously defined.

Equation (3) is when $\mathrm{EC}_{50}$ is zero the organism will have a normal life expectancy and it is related to the model constants as follows:

$$
\ln \mathrm{NLT}_{50}=b / a
$$

\subsection{Processing of Data}

The data sets for each teleost fish were used to evaluate the relationship between $\mathrm{EC}_{50}$ and $\operatorname{lnET} 50$ with the RLE model expressed in Equation (2). Thus $\mathrm{EC}_{50}$ was plotted against $\operatorname{lnET_{50}}$ and linear regression analysis was used to obtain the regression equation and the correlation coefficient $\left(\mathrm{R}^{2}\right)$ using Origin software (Microcal Software Inc., Northampton, Massachusetts, USA). The values of the slope (a) and intercept $(b)$ were obtained from the regression equation (Table 2). These values were then used to obtain the calculated NLT of each organism by the use of Equation (3) (Table 3).

\section{Results and Discussions}

\subsection{Relationship of Exposure Time with Toxic Effects Based on the $\mathrm{EC}_{50}$ Values}

The plots of $\operatorname{lnET_{50}}$ against $\mathrm{EC}_{50}$ based on Equation (2) are shown in Figure 1,

Table 2. Characteristics of the regression equation relating $\mathrm{EC}_{50}$ to $\ln \mathrm{ET}_{50}$ for the endocrine disrupters.

\begin{tabular}{cccc}
\hline Compounds & Slop $(a)^{1}$ & Intercept $(b)^{2}$ & Regression coefficient $\left(\mathrm{R}^{2}\right)$ \\
\hline $\mathrm{E}_{2}$ & $-3.91 \mathrm{E}-08$ & $1.20 \mathrm{E}-07$ & 0.5530 \\
$\mathrm{EE}_{2}$ & $-4.43 \mathrm{E}-08$ & $1.12 \mathrm{E}-07$ & 0.5735 \\
$\mathrm{BPA}$ & $-9.18 \mathrm{E}-05$ & $4.07 \mathrm{E}-04$ & 0.9264 \\
$\mathrm{NP}$ & $-1.37 \mathrm{E}-05$ & $4.22 \mathrm{E}-05$ & 0.8425 \\
\hline
\end{tabular}

The slope (a) and intercept $(b)$ were obtained from the regression equations. ${ }^{1} \mathrm{For}_{\mathrm{EC}} \mathrm{EC}_{50}=-\mathrm{a} \operatorname{lnET} \mathrm{T}_{50}+b .{ }^{2} \mathrm{For}$ $\operatorname{lnNLT} T_{50}=$ b/a. 
Table 3. Comparative analysis of calculated normal life expectancy and reported normal life expectancy.

\begin{tabular}{|c|c|c|c|c|c|}
\hline Fish & Compounds & Calculated NLT $(d)^{1}$ & Reported NLT ( $d$ ) & Slop (a) & $\begin{array}{c}\text { Regression } \\
\text { coefficient }\left(\mathrm{R}^{2}\right)\end{array}$ \\
\hline \multirow{4}{*}{ teleost fish } & $\mathrm{E}_{2}$ & 22 & $\begin{array}{c}\text { Zebrafish } 930-1350 \\
\text { [37] [38] [39] }\end{array}$ & 176.92 & 0.9202 \\
\hline & $\mathrm{EE}_{2}$ & 13 & $\begin{array}{c}\text { Fathead minnow } \\
540-1095[40]\end{array}$ & 177.67 & 0.9180 \\
\hline & $\mathrm{BPA}$ & 84 & $\begin{array}{l}\text { Brown trout } \\
1000-1400[41]\end{array}$ & 171.75 & 0.9349 \\
\hline & NP & 22 & $\begin{array}{l}\text { Rainbow Trout } \\
730-1095[42]\end{array}$ & 176.92 & 0.9202 \\
\hline
\end{tabular}

${ }^{1}$ For $\operatorname{lnNLT} T_{50}=b / a$.

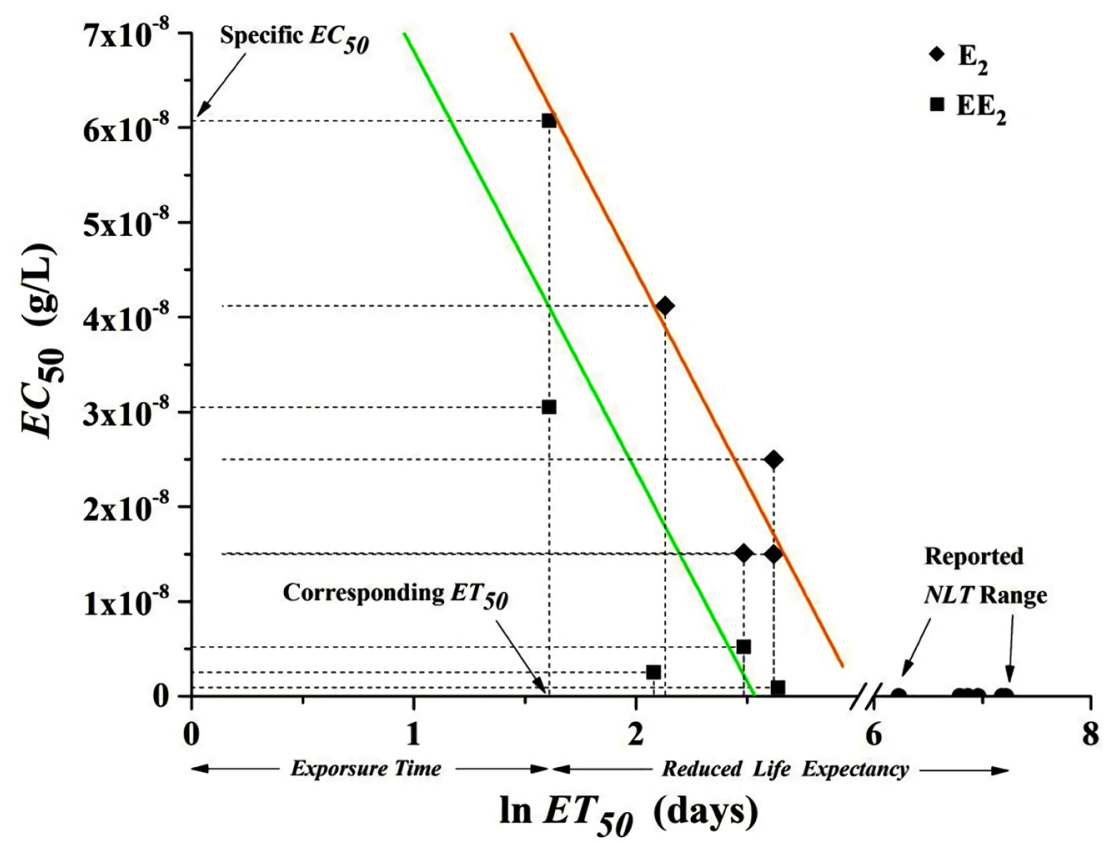

Figure 1. Plots of $\mathrm{EC}_{50}$ versus $\ln \mathrm{ET}_{50}$ for teleost fish with linear regression lines for $\mathrm{E}_{2}$ and $\mathrm{EE}_{2}$ data sets. Normal life expectancy (NLT) is indicated, where black dots on $\mathrm{x}$-axis represents reported NLT range of different types of teleost fishes. The orange and green lines are displayed as regression lines for $\mathrm{E}_{2}$ and $\mathrm{EE}_{2}$. The horizontal and vertical dash lines indicate specific $\mathrm{EC}_{50}$ values and corresponding $\mathrm{ET}_{50}$ values.

Figure 2. These plots utilize data from Table 2 on teleost fish for $\mathrm{EC}_{50}$ due to short-term exposure to endocrine disruptors. Plots for the $\mathrm{E}_{2}$ and $\mathrm{EE}_{2}$ are shown in Figure 1 and the corresponding plots for BPA and NP are shown in Figure 2. The characteristics of the relationships established using the regression equation can be used to compare the toxic effects of the E2, EE2, BPA and NP to teleost fish based on EC50 of hepatic biomarkers (Table 2). Table 2 indicates that slopes of $E_{2}, E_{2}$, BPA and NP between $-9.18 \mathrm{E}-05$ and $-3.91 \mathrm{E}-08$ and $\mathrm{R}^{2}$ value between 0.5530 and 0.9264 . The slopes of the regression equations reflect the strength of the toxic effects on the various teleost fish. Since the range of slopes obtained for the $\mathrm{E}_{2}$ and $\mathrm{EE}_{2}$ is from $-4.43 \mathrm{E}-08$ to $-3.91 \mathrm{E}-08$ while for the BPA 


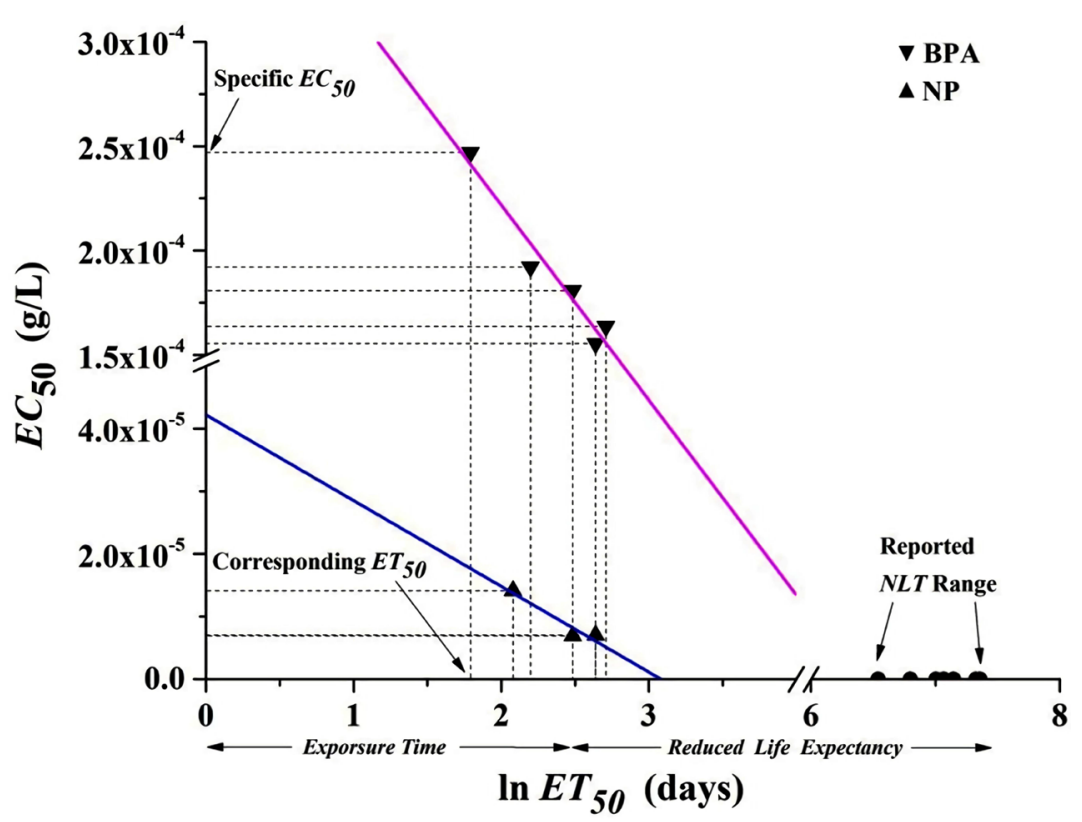

Figure 2. Plots of $\mathrm{EC}_{50}$ versus $\ln \mathrm{ET}_{50}$ for teleost fish with linear regression lines for BPA and NP data sets. Normal life expectancy (NLT) is indicated, where black dots on $\mathrm{x}$-axis represents reported NLT range of different types of teleost fishes. The magenta and blue lines are displayed as regression lines for BPA and NP. The horizontal and vertical dash lines indicate specific $\mathrm{EC}_{50}$ values and corresponding $\mathrm{ET}_{50}$ values.

and NP is from $-9.18 \mathrm{E}-05$ to $-1.37 \mathrm{E}-05$. The difference between the slopes is larger. Different toxic mechanisms involved with phenols and steroids may be responsible for this difference [22] [23]. Firstly, the observed $\mathrm{EC}_{50}$ of $\mathrm{E}_{2}$ and $\mathrm{EE}_{2}$ are often at the level of $\mathrm{ng} / \mathrm{L}$, and the observed $\mathrm{EC}_{50}$ of $\mathrm{BPA}$ and NP are often at the level of $\mu \mathrm{g} / \mathrm{L}$ (Table 1). Secondly, the interaction potential of $E_{2}$ was the most potent, followed by BPA and NP [5]; the estrogenic activity of $E_{2}$ was much higher than that of BPA and NP [24]; the estrogenic potential of $\mathrm{EE}_{2}$ was much higher than that of $E_{2}$, and the lowest observed effect concentration (LOEC) of $\mathrm{E}_{2}$ and $\mathrm{EE}_{2}$ is lower than BPA and NP [25]. And thus, the slops is comparatively higher for the $\mathrm{BPA}$ and $\mathrm{NP}$ than for the $\mathrm{E}_{2}$ and $\mathrm{EE}_{2}$, and the slops of $\mathrm{E}_{2}$ and $\mathrm{EE}_{2}$ is extremely small.

\subsection{Interpretation of the $\mathrm{EC}_{50}$ Reduction over Time Based on the Bioconcentration Process}

All the regression relationships have negative slopes (Table 2) which indicates that the $\mathrm{EC}_{50}$ of hepatic biomarkers is related to the exposure time and declines as the exposure time increases. These results are in accord which were studying the time dependent effects of $\mathrm{E}_{2}, \mathrm{BPA}$ and NP to zebrafish hepatic vtg1 gene [5]. Other researchers also reached the same conclusion while studying the toxic effects of organic pollutants to fish [12]. The transfer of compounds from water to fish is the first step in the development of toxic effects [26]. In fish the routes of compounds uptake are from gills, food and outer body surface but uptake of compounds takes place mainly via gills [27]. In Figure 3, compounds in water 


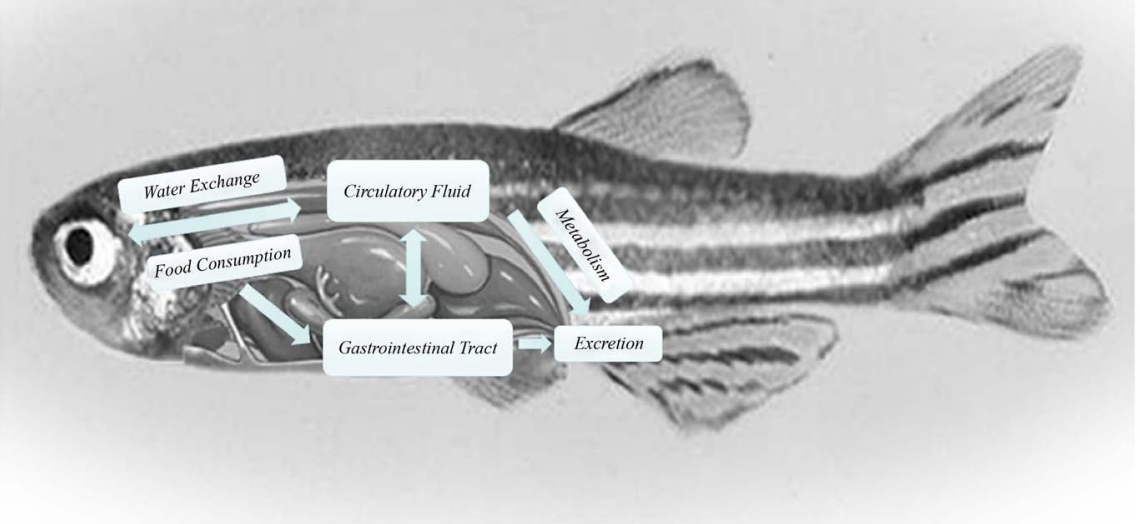

Figure 3. Diagram of routes of endocrine disrupters in teleost fishes.

can transfer from respiratory surfaces and gastrointestinal tract through circulatory fluid to liver in fish. In the process, some effect loss of the compounds, the compound continues to accumulate in the fish liver, and the increased metabolism of the hepatocytes and then the liver injury became exacerbated, these factors could be used to explain the decrease in the toxic effects over time. This was consistent with in previously studies [5] [28].

\subsection{Correlation between the Toxic Effects and Fish Life Expectancy Based on the Reported and Calculated NLT}

Calculated NLT is compared with reported NLT and calculated NLT differs from reported NLT (Table 3). Reported NLT and calculated NLT of teleost fish are in the range of $540-1400 \mathrm{~d}$ and $13-84 \mathrm{~d}$ respectively. The ratio of averages of reported NLT and calculated NLT is $1006 / 35$ and the standard deviation is $311 / 33$. The correlation coefficient $\left(\mathrm{R}^{2}\right)$ obtained from the plots of reported NLT against calculated NLT was greater than 0.91 in a general accord (Table 3 ). The results show that the correlation between reported NLT and calculated NLT is better. The NLT introduces a fixed limiting point for a teleost fish and it is a reference point for the reduced life expectancy in fish exposed to the compound [12]. In Figure 1, Figure 2, from the cross point of regression line and $\mathrm{x}$-axis to the roported NLT range, the trend changes of toxic effects based on the $\mathrm{EC}_{50}$ of hepatic biomarkers can be predicted by the RLE model when no data available for these extended exposure times. In other words, the toxic effects of a compound can be described using the RLE model and be corrected the experimental data to a specific time point. It is noteworthy that the days from the each exposure time point to the roported NLT range is the days in which fish life expectancy reduced after exposure to the compound (Figure 1, Figure $2 \mathrm{x}$-axis). These analyses were also referred in the previously RLE model studies [13] [29].

\section{Conclusion}

This study investigated the RLE model for teleost fish based on the toxicological 
data of endocrine disruptors available in the literature. Analogy of the RLE model can be useful to analyze the exposure time effects of teleost fish by using EC50 as toxicity endpoint and to understand routes of the EC50 reduction over time and effects of the toxic effects on fish life expectancy. The study method used may be extended to other fish species and even other organisms as well.

\section{Acknowledgements}

This study was financially supported by National Natural Science Foundation of China (Grant No. 41676110).

\section{Conflicts of Interest}

The authors declare no conflicts of interest regarding the publication of this paper.

\section{References}

[1] Michałowicz, J. (2014) Bisphenol A-Sources, Toxicity and Biotransformation. Environmental Toxicology and Pharmacology, 37, 738-758.

https://doi.org/10.1016/j.etap.2014.02.003

[2] Soares, A., Guieysse, B., Jefferson, B., Cartmell, E. and Lester, J.N. (2008) Nonylphenol in the Environment: A Critical Review on Occurrence, Fate, Toxicity and Treatment in Wastewaters. Environment international, 34, 1033-1049. https://doi.org/10.1016/j.envint.2008.01.004

[3] Yang, L., Zhou, B., Zha, J. and Wang, Z. (2016) Mechanistic Study of Chlordecone-Induced Endocrine Disruption: Based on an Adverse Outcome Pathway Network. Chemosphere, 161, 372-381. https://doi.org/10.1016/j.chemosphere.2016.07.034

[4] Zhao, F., et al. (2017) Estrogenic Effects Associated with Bisphenol a Exposure in Male Zebrafish (Danio rerio) Is Associated with Changes of Endogenous $17 \beta$-Estradiol and Gene Specific DNA Methylation Levels. General and Comparative Endocrinology, 252, 27-35. https://doi.org/10.1016/j.ygcen.2017.07.032

[5] Chen, H., Zhao, L. and Yu, Q.J. (2019) Determination and Reduced Life Expectancy Model and Molecular Docking Analyses of Estrogenic Potentials of 17 $\beta$-Estradiol, Bisphenol A and Nonylphenol on Expression of Vitellogenin Gene ( Vtg1) in Zebrafish. Chemosphere, 221, 727-734. https://doi.org/10.1016/j.chemosphere.2019.01.093

[6] Meylan, W.M., Howard, P.H., Boethling, R.S., Aronson, D., Printup, H. and Gouchie, S. (1999) Improved Method for Estimating Bioconcentration/Bioaccumulation Factor from Octanol/Water Partition Coefficient. Environmental Toxicology and Chemistry, 18, 664-672. https://doi.org/10.1002/etc.5620180412

[7] Ying, G.-G., Williams, B. and Kookana, R. (2002) Environmental Fate of Alkylphenols and Alkylphenol Ethoxylates-A Review. Environment International, 28, 215 226. https://doi.org/10.1016/S0160-4120(02)00017-X

[8] Segner, H., et al. (2003) Identification of Endocrine-Disrupting Effects in Aquatic Vertebrates and Invertebrates: Report from the European IDEA Project. Ecotoxicology and Environmental Safety, 54, 302-314. https://doi.org/10.1016/S0147-6513(02)00039-8

[9] Wittbrodt, J., Shima, A. and Schartl, M. (2002) Medaka-A Model Organism from 
the Far East. Nature Reviews Genetics, 3, 53-64. https://doi.org/10.1038/nrg704

[10] Chen, M., et al. (2018) Evaluating Estrogenic and Anti-Estrogenic Effect of Endocrine Disrupting Chemicals (EDCs) by Zebrafish (Danio rerio) Embryo-Based Vitellogenin 1 (Vtg1) Mrna Expression. Comparative Biochemistry and Physiology Part C: Toxicol \& Pharmacol, 204, 45-50. https://doi.org/10.1016/j.cbpc.2017.11.010

[11] Teta, C. and Naik, Y.S. (2017) Vitellogenin Induction and Reduced Fecundity in Zebrafish Exposed to Effluents from the City of Bulawayo, Zimbabwe. Chemosphere, 167, 282-290. https://doi.org/10.1016/j.chemosphere.2016.10.011

[12] Connell, D.W., Yu, Q.J. and Verma, V. (2016) Influence of Exposure Time on Toxicity-An Overview. Toxicology, 355-356, 49-53. https://doi.org/10.1016/j.tox.2016.05.015

[13] Verma, V., Yu, Q.J. and Connell, D.W. (2013) Reduced Life Expectancy Model for Effects of Long Term Exposure on Lethal Toxicity with Fish. ISRN Toxicology, 2013, Article ID: 230763. https://doi.org/10.1155/2013/230763

[14] Sargent, J.R. (1997) Fish Oils and Human Diet. British Journal of Nutrition, 78, S5S13. https://doi.org/10.1079/BJN19970131

[15] Tocher, D.R., Bendiksen, E.Å., Campbell, P.J. and Bell, J.G. (2008) The Role of Phospholipids in Nutrition and Metabolism of Teleost Fish. Aquaculture, 280, 21-34. https://doi.org/10.1016/j.aquaculture.2008.04.034

[16] Cortés, E. (1999) Standardized Diet Compositions and Trophic Levels of Sharks. ICES Journal of Marine Science, 56, 707-717. https://doi.org/10.1006/jmsc.1999.0489

[17] Villeneuve, D.L., et al. (2012) Ecotoxicogenomics to Support Ecological Risk Assessment: A Case Study with Bisphenol A in Fish. Environmental Science \& Technology, 46, 51-59. https://doi.org/10.1021/es201150a

[18] Bissell, D.M., Gores, G.J., Laskin, D.L. and Hoofnagle, J.H. (2001) Drug-Induced Liver Injury: Mechanisms and Test Systems. Hepatology, 33, 1009-1013. https://doi.org/10.1053/jhep.2001.23505

[19] Guo, Q., et al. (2014) Study on Early Biomarkers of Zebrafish Liver Injury Induced by Acetaminophen. Toxin Reviews, 34, 28-36.

https://doi.org/10.3109/15569543.2014.986282

[20] Verma, V., Yu, Q.J. and Connell, D.W. (2015) A Comparison of Reduced Life Expectancy (RLE) Model with Haber's Rule to Describe Effects of Exposure Time on Toxicity. Environmental Pollution, 204, 26-31. https://doi.org/10.1016/j.envpol.2015.04.008

[21] Verma, V., Yu, Q.J. and Connell, D.W. (2014) Evaluation of Effects of Long Term Exposure on Lethal Toxicity with Mammals. Environmental Pollution, 185, 234-239. https://doi.org/10.1016/j.envpol.2013.11.001

[22] Casals-Casas, C. and Desvergne, B. (2011) Endocrine Disruptors: from Endocrine to Metabolic Disruption. Annual Review of Physiology, 73, 135-162. https://doi.org/10.1146/annurev-physiol-012110-142200

[23] De Coster, S. and Van Larebeke, N. (2012) Endocrine-Disrupting Chemicals: Associated Disorders and Mechanisms of Action. Journal of Environmental and Public Health, 2012, Article ID: 713696. https://doi.org/10.1155/2012/713696

[24] Routledge, E.J. and Sumpter, J.P. (1996) Estrogenic Activity of Surfactants and Some of their Degradation Products Assessed Using A Recombinant Yeast Screen. Environmental Toxicology and Chemistry, 15, 241-248. https://doi.org/10.1002/etc. 5620150303 
[25] Woods, M. and Kumar, A. (2011) Vitellogenin Induction by $17 \beta$-Estradiol and $17 \alpha$-Ethynylestradiol in Male Murray Rainbowfish (Melanotaenia fluviatilis). Environmental Toxicology and Chemistry, 30, 2620-2627. https://doi.org/10.1002/etc.660

[26] Connell, D.W. (1995) Prediction of Bioconcentration and Related Lethal and Sublethal Effects with Aquatic Organisms. Marine Pollution Bulletin, 31, 201-205. https://doi.org/10.1016/0025-326X(96)81925-4

[27] Connell, D.W. (1988) Bioaccumulation Behavior of Persistent Organic Chemicals with Aquatic Organisms. In: Ware, G.W., Ed., Reviews of Environmental Contamination and Toxicology, Vol. 102, Springer, Berlin, 117-154. https://doi.org/10.1007/978-1-4612-3810-2 3

[28] Lindholst, C., Wynne, P.M., Marriott, P., Pedersen, S.N. and Bjerregaard, P. (2003) Metabolism of Bisphenol A in Zebrafish (Danio rerio) and Rainbow Trout (Oncorhynchus mykiss) in Relation to Estrogenic Response. Comparative Biochemistry and Physiology Part C: Toxicology \& Pharmacology, 135, 169-177. https://doi.org/10.1016/S1532-0456(03)00088-7

[29] Connell, D. and Yu, J. (2008) Use of Exposure Time and Life Expectancy in Models for Toxicity to Aquatic Organisms. Marine Pollution Bulletin, 57, 245-249. https://doi.org/10.1016/j.marpolbul.2008.03.034

[30] Rose, J., Holbech, H., Lindholst, C., Nørum, U., Povlsen, A., Korsgaard, B. and Bjerregaard, P. (2002) Vitellogenin Induction by $17 \beta$-Estradiol and $17 \alpha$-Ethinylestradiol in Male Zebrafish (Danio rerio). Comparative Biochemistry and Physiology Part C: Toxicology \& Pharmacology, 131, 531-539. https://doi.org/10.1016/S1532-0456(02)00035-2

[31] Bjerregaard, P., Hansen, P.R., Larsen, K.J., Erratico, C., Korsgaard, B. and Holbech, H. (2008) Vitellogenin as a Biomarker for Estrogenic Effects in Brown Trout, Salmo Trutta: Laboratory and Field Investigations. Environmental Toxicology and Chemistry, 27, 2387-2396. https://doi.org/10.1897/08-148.1

[32] Thorpe, K.I., Hutchinson, T.H., Hetheridge, M.J., Sumpter, J.P. and Tyler, C.R. (2000) Development of an in Vivo Screening Assay for Estrogenic Chemicals Using Juvenile Rainbow Trout (Oncorhynchus mykiss). Environmental Toxicology and Chemistry, 19, 2812-2820. https://doi.org/10.1002/etc.5620191128

[33] Brian, J.V., et al. (2005) Accurate Prediction of the Response of Freshwater Fish to a Mixture of Estrogenic Chemicals. Environmental Health Perspectives, 113, 721-728. https://doi.org/10.1289/ehp.7598

[34] Muncke, J., Junghans, M. and Eggen, R.I. (2007) Testing Estrogenicity of Known and Novel (Xeno-)Estrogens in the Moldart Using Developing Zebrafish (Danio rerio). Environmental Toxicology, 22, 185-193. https://doi.org/10.1002/tox.20255

[35] Bakos, K., et al. (2019) Estrogen Sensitive Liver Transgenic Zebrafish (Danio rerio) Line ( $\operatorname{Tg}(V \operatorname{tg} 1: m C h e r r y))$ Suitable for the Direct Detection of Estrogenicity in Environmental Samples. Aquatic Toxicology, 208, 157-167. https://doi.org/10.1016/j.aquatox.2019.01.008

[36] Lech, J.J., Lewis, S.K. and Ren, L. (1996) In Vivo Estrogenic Activity of Nonylphenol in Rainbow Trout. Toxicological Sciences, 30, 229-232.

https://doi.org/10.1093/toxsci/30.2.229

[37] Dede, A. (2017) Expression of Key Synaptic Proteins in Zebrafish (Danio rerio) Brain Following Caloric Restriction and Its Mimetic and Their Relationship with Gender. Neuroscience Letters, 383, 99-104.

[38] Gerhard, G.S. and Cheng, K.C. (2002) A Call to Fins! Zebrafish as a Gerontological 
Model. Aging Cell, 1, 104-111. https://doi.org/10.1046/j.1474-9728.2002.00012.x

[39] Herrera, M. and Jagadeeswaran, P. (2004) Annual Fish as a Genetic Model for Aging. The Journals of Gerontology Series A: Biological Sciences and Medical Sciences, 59, B101-B107. https://doi.org/10.1093/gerona/59.2.B101

[40] Spromberg, J.A. and Birge, W.J. (2005) Modeling the Effects of Chronic Toxicity on Fish Populations: The Influence of Life-History Strategies. Environmental Toxicology and Chemistry, 24, 1532-1540. https://doi.org/10.1897/04-160.1

[41] Lobón-Cerviá, J. (2005) The Importance of Recruitment for the Production Dynamics of Stream-Dwelling Brown Trout (Salmo trutta). Canadian Journal of Fisheries and Aquatic Sciences, 62, 2484-2493. https://doi.org/10.1139/f05-166

[42] Sadoul, B., Augustine, S., Zimmer, E., Bégout, M.-L. and Vijayan, M.M. (2019) Prediction of Long-Term Variation in Offspring Metabolism Due to BPA in Eggs in Rainbow Trout Using the DEB Model. Journal of Sea Research, 143, 222-230. https://doi.org/10.1016/j.seares.2018.05.011 